\title{
Evacuation Model for Merging Traffic Flows in Multi- Room and Multi-Storey Buildings
}

\author{
V. O. SHESTOPAL and S. J. GRUBITS \\ Commonwealth Scientific and Industrial Research Organisation, Division of Building, \\ Construction and Engineering, P.O. Box 310, North Ryde, N.S.W., Australia
}

\begin{abstract}
A program WAYOUT has been created to compute traffic flow in emergency situations from a multi-room and, possibly, multi-storey building. Only merging traffic flows are considered. In case of branching flows, a user is required to draw watersheds to divide the flows and compute them separately.

The model is based on movement speed - density dependence derived by Predtechenskii \& Mininskii [ $\left.{ }^{1}\right]$ and takes into account a number of non-linear interactions of flows from different rooms. Only flows of healthy people are considered. Psychological factors are not attended to.

Program WAYOUT can be run on an IBM PC or a compatible computer. The "Windows" version features traffic network visualisation and evacuation process animation. Computed are: maximum times of evacuation from the blind ends and times of complete evacuation from each room.
\end{abstract}

KEYWORDS: Egress, Evacuation, Computer software.

\section{INTRODUCTION}

There are several methods and computer programs developed to compute evacuation time from large public buildings. Each of them has some drawbacks that make further development desirable.

Nelson and McLennan propose an analytical approach [ $\left.{ }^{2}\right]$ which is not intended to be extrapolated to complex network of exit routes.

Program EVACNET $+\left[{ }^{3}\right]$ uses constant walking speeds chosen by a user for each compartment and does not address door-to-door distances in detail.

Program EXIT89 $\left[{ }^{4}\right]$ utilises the results of the comprehensive study by Predtechenskii and Milinskii [l] who measured foot traffic speeds in a vast range of flow densities and other conditions. This program written for an IBM mainframe is not yet available commercially.

Program EXITT, part of Hazard I [5], uses traffic speeds which depend on fire conditions, but do not depend on traffic flow density. This model is currently limited to 12 rooms and 35 nodes. 


\section{PROGRAM DESCRIPTION}

Program WAYOUT, like EXIT89 [ ${ }^{4}$, is based on the speed data collected by Predtechenskii and Milinskii [ $\left.{ }^{1}\right]$. In accordance with this source, dimensionless flow density $D$ is defined as

$D=N f / w L$

where $N$ is number of people in the stream, $f$ - area of horizontal projection of a person, $w$ width and $L$ - length of the stream. It is assumed that for an adult in mid-season dress $f=$ $0.113 \mathrm{~m}^{2}$ and maximum density $D_{\max }=0.92$. According to $\left.{ }^{1}\right]$, traffic speeds $v$ decrease with increasing density and flow $F$ defined as

$F=v D w / f \quad$ persons $/ \mathrm{min}$

has a maximum at certain density (see Figure 1), which depends on the geometry of the passage (level passage, stairs, door). This is a cause of instability of the foot traffic: if density exceeds critical value $D_{c r}$ corresponding to the maximum flow, a local increase of density would cause slowing of the flow, which would produce further densification until $D_{\max }$ has been reached. Therefore, it is assumed in the program that if density reaches $D_{c r}$, it changes abruptly to $D_{\max }$. In $\left[^{1}\right]$ the stairs are assumed to be of standard steepness, so that neither riser nor tread size variations are considered.

Program WAYOUT considers up to 200 rooms connected in a merging network towards a single exit. The restriction in the room numbers has been introduced arbitrarily, to limit computer memory requirements, and can be extended if necessary. Limiting the model to a merging network changes the problem from a probabilistic one to a deterministic one. The complexity of existing models, like EVACNET $+\left[{ }^{3}\right]$ and EXIT89 $\left[{ }^{4}\right]$, is due to the necessity of applying the combinatorial analysis, queuing theory etc as described by Watts $\left[{ }^{6}\right]$. In most practical cases, skipping of branching flows can be offset by choosing watersheds within the network of compartments and by approximating two parallel corridors or stairs by one with equivalent width and length. On the other hand, finding the minimum evacuation time routes has little to do with reality, because research has shown $\left[{ }^{7}\right]$ that people tend to choose the evacuation routes on the basis of psychological factors, such as memory of their entry routes, marking of the emergency exits etc, which can hardly be expected to coincide with the mathematically optimised routes. Restricting the program to merging flows has allowed it to be built in a recursive way, thereby simplifying the process of entering data and arranging rooms. Each room is assumed to have its own single exit door (the width of which might be equal to that of the room). This scheme also has the advantage of enabling description of the traffic through each passage in greater detail. Whereas EVACNET+ describes each node by its traversal time, irrespective of the number and location of doors, WAYOUT considers flows from door to door.

We shall refer to a compartment of constant width with its exit door as a twig. If a compartment has a variable width, it is divided into two or more twigs. Traffic within each twig is from the entrance to the exit door. Several entrance doors can lead into a twig, but no intermediate doors are considered. If a passage has an intermediate door, it is to be divided into two twigs. The number of doors at the entrance is referred to as Number of merging streams. This number can vary from 0 to 9 , zero being for blind ends. 
The core of the program is a recursive procedure Twig 0 , which starts execution at Twig 1 and calls itself as many times as the number of merging streams. Hence, execution proceeds round the twig tree, limited by the merging streams.

It is assumed that people initially located in one twig enter the next twig on their way to the final exit in compact packs. Within each twig, for each pack passing the twig, four time marks are considered: head and tail times of entry of each pack into the twig, and head and tail times of exit of each pack from the twig. As a common case, several packs are situated in a twig at each time point. Also, several packs are entering each door simultaneously. This enables us to compute velocities of movement within a twig and velocities of entry into the twig on the basis of population density, according to Predtechenskii and Milinskii [ $\left.{ }^{1}\right]$ (see Figure 1).

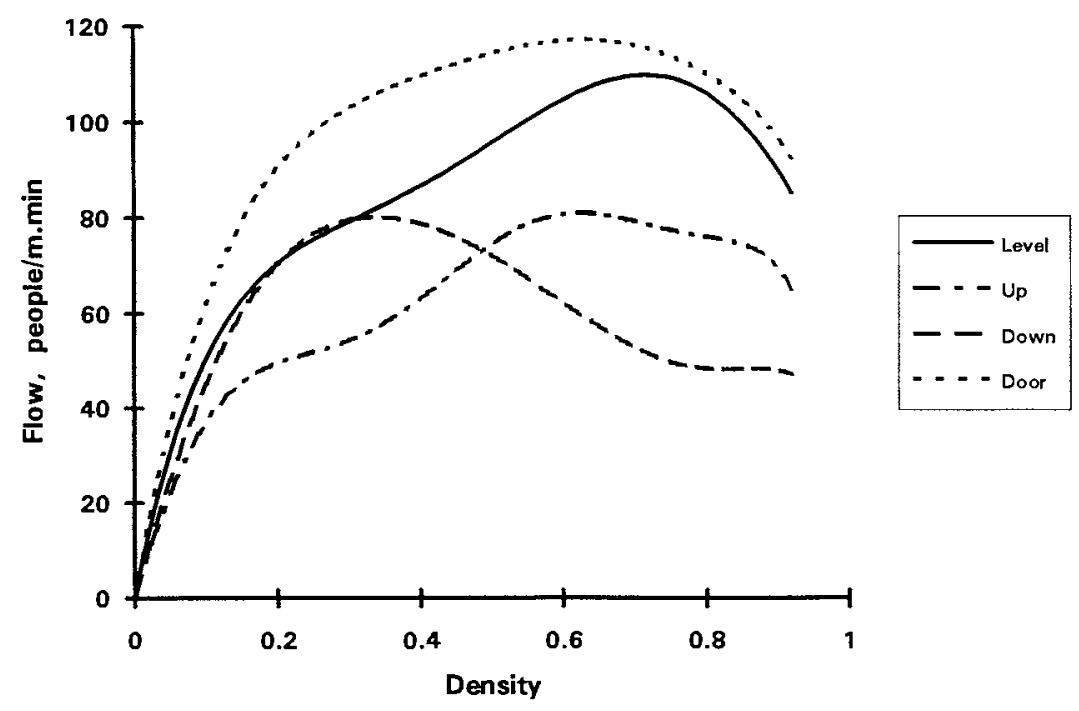

FIGURE 1. Flow of the emergency exit traffic as a function of flow density $\left.{ }^{1}{ }^{1}\right]$

When a new pack enters a twig, speed of movement decreases, because of increase in density. Accordingly, when a pack exits a twig completely, the movement speeds up. When the tail of a pack enters a door, speed at the door will increase. However, it is assumed that no overtaking can occur, and if faster evacuees appear in a compartment where high density at the exit slows evacuation down, the newcomers join the queue.

Another complication is the case when the exit door from a twig is narrow, and all the compartment is filled with people at maximum density. Obviously, entry speeds based upon the width of entry doors must be corrected. In fact, procedure Twig0 considers a number of similar recalculations. 


\section{USER INTERFACE}

Figure 2 shows an example of a two-storey building with twigs marked. Each twig is numbered. The program assigns twig numbers automatically, starting from the final exit. Final exit twig always has number 1 . Then each twig is marked by the number of the twig along the flow plus one digit, starting from $l$ and up to the number of merging streams. For instance, in Figure 2, twig 112 has two merging streams marked 1121 and 1122 . For each twig, the user enters door width, compartment length and width, number of merging streams and number of evacuees initially located in the compartment. If the twig is a blind end, the user also enters start time of evacuation. This enables the user to take into account delays in starting of the orderly evacuation due to delays in receiving an alarm cue. For intermediate twigs, it is assumed that evacuation of the initial residents of the twig starts when first evacuees who are already on the move appear in the room. Such an assumption is the most conservative estimation of the evacuation time. For each compartment, the program computes the time when the last evacuee has left. For blind ends, maximum egress time from the initial location to the final exit is computed.

Program WAYOUT is one of the modules of the fire safety engineering package FIRECALC. In its most complete form, it is written for FIRECALC 3.0, which runs under Microsoft Windows. Accordingly, all the usual user-friendly Windows interface is available. The twig tree can be visualised. Figure 3 shows the tree for the building of Figure 2 . In the course of recursive programming, computation proceeds round the tree presented in the figure clockwise and the twigs are placed on the input screen and in the printout in the same order.

The process of evacuation can be animated, so that the situation at each tick of the simulation clock can be observed on the screen. Figure 4 shows an example of the printout for the building presented in Figure 2. The entries and the results can also be saved in a computer file and to the clipboard and can be readily included in any document created by Windows compatible software, such as Microsoft Word-for-Windows.
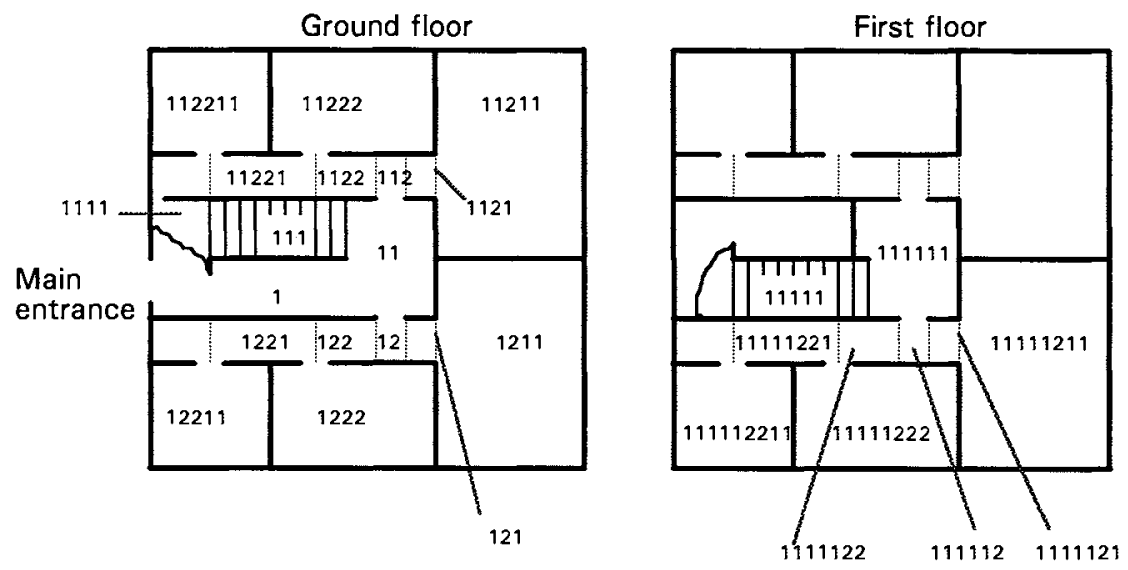

FIGURE 2. Two-storey building used in the example calculation. Twig numbers marked. 
Tree of evacuation route

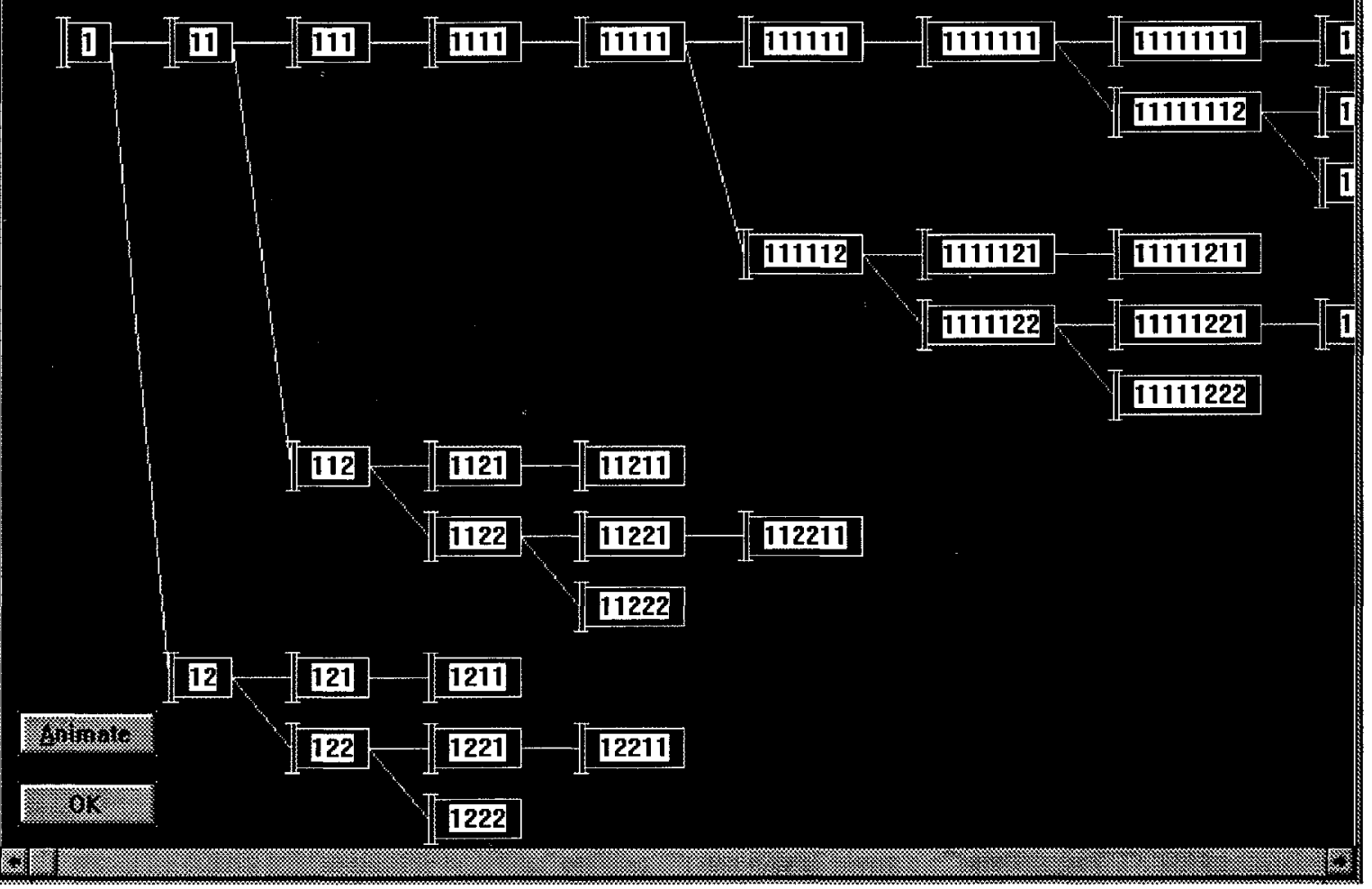

FIGURE 3. Calculation tree for the example building of Figure 2 as displayed in the screen. 


\section{TESTING THE MODEL}

The evacuation study on Milburn House, Newcastle upon Tyne (UK), was provided to us by Tyne and Wear Metropolitan Fire Brigade. This study was conducted as a fire drill. Milburn House is a seven storey office building. Evacuation was facilitated through several exit doors. At each exit, the number of evacuees was monitored and time of the first and the last arrival measured.

TABLE. Comparison of fire drill results with computation.

\begin{tabular}{|c|c|c|c|c|c|}
\hline & \multirow{2}{*}{ Number of evacuees } & \multicolumn{2}{c|}{ Time of the gap in flow } & \multicolumn{2}{c|}{ Time of evacuation } \\
\hline & & Tested & Computed & Tested & Computed \\
\hline Exit 10 & 248 & $3^{\prime} 40^{\prime \prime}$ & $2^{\prime} 48^{\prime \prime}$ & $4^{\prime} 26^{\prime \prime}$ & $4^{\prime} 03^{\prime \prime}$ \\
\hline Exit 4 & 40 & - & - & $1^{\prime} 00^{\prime \prime}$ & $0^{\prime} 40^{\prime \prime}-1^{\prime} 39^{\prime \prime}$ \\
\hline Exit 8 & 48 & - & - & $2^{\prime} 36^{\prime \prime}$ & $2^{\prime} 44^{\prime \prime}$ \\
\hline
\end{tabular}

The comparison of the test data with the computed results is shown in Table. The calculations have been made for three exits through which a significant number of evacuees had passed. Through each of the other exits less than 20 people passed, which makes comparison unconvincing. The records of the test made in the real life situation are inevitably incomplete: not all the occupants had returned their questionnaires, hence their initial locations in the building could not be identified; there are minor discrepancies in the records with regard to the number of people that passed through the stairs and exit doors. This uncertainty gave some room for different interpretations, which are reflected in the data for Exit 4. Depending on the initial location of the occupants, the evacuees could build into a dense crowd on the stairs, or could not. So both results are shown in the table. Also bearing in mind that the program does not take into account initial time loss between receiving a cue and starting of evacuation, the time difference between the arrival of the first evacuee and the last one is shown as the evacuation time. This initial time loss would be approximately 20 seconds for the considered fire drill. It is also probable that during the drill people did not moved as fast as they would in a real emergency situation. This can explain some tendency of the computed times to be lower than test results. According to Predtechenskii and Milinskii [l], speed difference can be about $20 \%$, but the results cannot be multiplied by this coefficient in a straightforward manner because the algorithm is mathematically non-linear. Considering these limitations, the comparison seems to be satisfactory. 
FireCalc 3.0

CSIRO, div. BCE, North Ryde, N.S.W., Australia

update 20 January 1994

licensed to CSIRO, div. BCE (North Ryde)

Program Fayout

\begin{tabular}{|c|c|c|c|c|c|c|c|c|c|}
\hline Twig & $\begin{array}{l}\text { Door } \\
\text { width } \\
\text { m }\end{array}$ & $\begin{array}{l}\text { Slope } \\
\text { (Level, } \\
\text { Up, Down) }\end{array}$ & $\begin{array}{l}\text { Length } \\
\text { m }\end{array}$ & $\begin{array}{l}\text { Width } \\
\text { In }\end{array}$ & $\begin{array}{l}\text { Number of } \\
\text { merging } \\
\text { streams }\end{array}$ & $\begin{array}{l}\text { Humber of } \\
\text { evacuees }\end{array}$ & $\begin{array}{l}\text { Start } \\
\text { time } \\
s\end{array}$ & $\begin{array}{l}\quad \text { Time, mi } \\
\text { last evacuee } \\
\text { left at... }\end{array}$ & $\begin{array}{l}\text { Mates: } \\
\text { Maxims } \\
\text { eqress time }\end{array}$ \\
\hline 1 & 1.20 & Level & 9.00 & 1.50 & 2 & 0 & & 2.20 & \\
\hline 11 & 1.50 & Level & 1.50 & 1.50 & 2 & 0 & & 2.06 & \\
\hline 111 & 1.50 & Down & 6.70 & 1.50 & 1 & 0 & & 2.04 & \\
\hline 1111 & 1.50 & Lerel & 1.50 & 1.50 & 1 & 0 & & 1.92 & \\
\hline 11111 & 1.50 & Dosn & 6.70 & 1.50 & 2 & 0 & & $\$ .89$ & \\
\hline 111111 & 1.50 & Level & 1.50 & 2.00 & 1 & 0 & & 0.64 & \\
\hline 1111111 & 0.85 & Lerel & 1.50 & 1.50 & $\partial$ & 0 & & 0.34 & \\
\hline 1111111 & 1.50 & Letel & 1.00 & 1.50 & 1 & 0 & & 0.15 & \\
\hline 111111111 & 0.85 & Level & 6.00 & 7.00 & 0 & 10 & 0 & 0.13 & 2.10 \\
\hline 11111112 & 1.50 & Level & 2.00 & 1.50 & 2 & 0 & & 0.24 & \\
\hline 11111121 & 1.50 & Level & 4.00 & 1.50 & 1 & 0 & & 0.14 & \\
\hline 111111211 & 0.85 & Level & 4.00 & 4.00 & 0 & 5 & 0 & 0.06 & 2.10 \\
\hline 11111122 & 0.85 & Level & 6.00 & 4.00 & 0 & 7 & 0 & 0.09 & 2.17 \\
\hline 11112 & 0.85 & Level & 1.50 & 1.50 & 2 & 0 & & 0.67 & \\
\hline 1111121 & 1.50 & Lerel & 1.00 & 1.50 & 1 & 0 & & 0.15 & \\
\hline$\$ 111: 211$ & 0.85 & Lerel & 6.00 & 7.00 & 0 & 10 & 0 & 0.13 & 1.68 \\
\hline$\vdots 111 \pm 22$ & 1.50 & Lerel & 4.00 & 1.50 & 2 & 0 & & 0.35 & \\
\hline 11111221 & 1.50 & Lerel & 4.00 & 1.50 & 1 & 0 & & 0.14 & \\
\hline $111 \geq 12211$ & 0.85 & Level & 4.00 & 4.00 & 0 & 5 & 0 & 0.06 & 2.11 \\
\hline 11111222 & 0.85 & Lerel & 6.00 & 4.00 & 0 & 7 & 0 & 0.09 & 2.20 \\
\hline 112 & 0.85 & Lerel & 1.50 & 1.50 & 2 & 0 & & 0.34 & \\
\hline 12: & 1.50 & Level & 1.00 & 1.50 & 1 & 0 & & 0.15 & \\
\hline $112: 3$ & 0.85 & Level & 6.00 & 7.00 & 0 & 10 & 0 & 0.13 & 0.62 \\
\hline 1222 & 1.50 & Level & 2.00 & 1.50 & 2 & 0 & & 0.24 & \\
\hline :12z: & 1.50 & Level & 4.00 & 1.50 & 1 & 0 & & 0.14 & \\
\hline$: 122: 1$ & 0.85 & Level & 4.00 & 4.00 & 0 & 5 & 0 & 0.06 & 0.85 \\
\hline$: 1222$ & 0.85 & Lerel & 6.00 & 4.00 & 0 & $?$ & 0 & 0.09 & 0.85 \\
\hline$\vdots 2$ & 0.85 & Lerel & 1.50 & 5.00 & 2 & 0 & & 0.33 & \\
\hline 121 & 1.50 & Level & 1.00 & 1.50 & 1 & 0 & & 0.15 & \\
\hline :21: & 0.85 & Lerel & 6.00 & 7.00 & 0 & 10 & 0 & 0.13 & 0.40 \\
\hline 122 & 1.50 & Level & 2.00 & 1.50 & 2 & 0 & & 0.24 & \\
\hline $122:$ & 1.50 & Level & 4.00 & 1.50 & 1 & 0 & & 0.14 & \\
\hline$i 22: 3$ & 0.85 & Lerel & 4.00 & 4.00 & 0 & 5 & 0 & 0.06 & 0.80 \\
\hline 1222 & 0.85 & Level & 6.00 & 4.00 & 0 & 7 & 0 & 0.09 & 0.83 \\
\hline
\end{tabular}

FIGURE 4. Printout for the evacuation from the building, Figure 2. 


\section{ACKNOWLEDGMENTS}

The authors are grateful to Mr. Richard Allan from Tyne and Wear Metropolitan Fire Brigade for making available to us the results of the fire drill and his valuable advice. The authors appreciate the contribution of those users of FIRECALC whose critical comments enabled us to make important improvements to the program.

\section{CONCLUSION}

Program WAYOUT, being part of FIRECALC package, has been in use in Australia for several years and was applied in practical engineering situations to such cases as multistorey buildings, stadiums and malls, as well as miscellaneous simpler cases.

\section{REFERENCES}

1. Predtechenskii, V.M. and Milinskii, A.I. Planning for Foot Traffic Flow in Buildings. Amerind Publishing Company, Inc., New Delhi, 1978.

2. Nelson, H.E. and MacLennan, H.A. Emergency movement, in SFPE Handbook of Fire Protection Engineering, p. 2-106, NFPA \& SFPE, 1988.

3. Kisko, T.M., Francis, R.L. and Noble, C.R. EVACNET+ User's Guide, Department of Industrial and System Engineering, University of Florida, Gainesville, Florida, 1984.

4. Fahy, R.F. "EXIT89 - an evacuation model for high-rise buildings", in Interflam '93 Fire Safety Proceedings, p. 519, Interscience Communications Ltd., London 1993.

5. Bukowski, R.W., Jones, W.W., Levin, B.M., Forney, C.L., Steifel, S.W., Babrauskas, V., Braun, E., Fowell, A.J. HAZARD I - Volume I: Fire Hazard Assessment Method, National Institute of Standards and Technology Center for Fire Research, NBSIR 87-3602, July 1987.

6. Watts, J.M., Jr. "Computer models for evacuation analysis", Fire Safety Journal, $12,237-245,1987$.

7. Ozel, F. Way Finding and Route Selection in Fires. School of Architecture, New Jersey Institute of Technology, Newark, 1986. 